\title{
TERRITORIAL DIFFERENCES IN TRANSFORMATION PROCESSES IN BULGARIA
}

\author{
Margarita ILIEVA \\ National Institute of Geophysics, Geodesy and Geography, Bulgarian Academy of \\ Sciences, Bulgaria; Institute of Geography, Kazimierz Wielki University \\ Bydgoszcz, Poland
}

\begin{abstract}
The transformation processes in Central and Eastern Europe, including Bulgaria, are subject of many investigations in the last two decades. Up to now there is no geographical survey on the territorial differences and their course in Bulgaria. The aim of this investigation is to study these differences in the transformation process in Bulgaria by 28 administrative districts (NUTS3). On the basis of analyses and comparisons of GDP per capita in different units (an indicator, accepted by specialists as the most common parameter) and the calculated values of integral indicator (reflecting the influence of 15 interlocked factors), the existing significant differences in the achieved level of transformation in the country are shown. At this stage there is no sufficient research to determine the threshold value of the integral indicator and to say with certainty that the territorial units, having values above it, are winners from the transformation process, and those with values below it, are losers.
\end{abstract}

Key Words: territorial differences, transformation, Bulgaria

\section{Introduction}

The transformation started in all territorial units first in the economy and the changes in the economic sphere are connected with changes in the social sphere. Some of them are identical in nature with the changes in the national economy, while others are different. In general, the peculiarities of the process of transformation are a result of overlapping of national trends and specific processes and phenomena in the development of different parts of the country.

Several researchers determine the causes and factors that have influenced the different duration and effectiveness of the transformation process and the transition to a market economy. As Rydz (2006) maintains, the contemporary transformation processes are carried out in terms of pushing the regional structures out of the previous central command system and lead to the creation of new structures, based on market rules. "The effects of factors of restructuring in the geographic space build upon regional structures, formed earlier, which are characterized by different conditions for the adoption and implementation of the rules of the new system. New regional systems are formed as a result of the stronger but varying impact of new internal factors arising from the transformation process, and also of the factors at national and international level "(p. 5). According to Ciok (2001) "transformation process had a strong regional differentiation of forms from the very beginning" (p. 35), and according to Enyedi (2005) „regional disparities are evident, because of the uneven geographical distribution of development resources" (c. 18). Furthermore, it should be noted that the process of transformation of regional structures is carried out in a particular geographical environment, 
which is a function of interrelated elements of the natural, social, economic and cultural space (Zioło 1998).

\section{Material and Methods}

As basic units in this study of regional differences in the transformation process are used the 28 districts, created in 1999, to replace previously existing nine larger administrative districts. The change of administrative division and the establishment of planning regions as new territorial framework and organizational structure for future sustainable and balanced regional development in compliance with the process of integration of Bulgaria into the European structures and for carrying out relevant regional policy can be evaluated as a specific aspect of transformation in the country.

From the analysis of publications, in which the processes of transformation are a major subject of research, or of publications evaluating the differences in the level of socio-economic development during the transformation, it becomes obvious that the researchers have the used both single indicators and a combination of different number of indicators. As to the nature of the indicators that can measure the transformation, according to Conford, Richardson, Sokol, Marques, Gillespie (2006) there are well established and relatively non-contentious measures of improvement of transformed units - Gross Domestic / Regional Product per capita, various measures of productivity (output per worker or per working hour), levels of unemployment, levels of social exclusion, life expectancy, etc. Apparently, most of these indicators can be measured quantitatively. At first glance it seems that some of them imply expectations of negative consequences of transformation process, as unfortunately was the actual situation at the beginning of transition in Central and Eastern Europe. But as these authors stress, the transformation is expected to lead to improvements in transforming units, i.e. to have a positive contribution.

Gross domestic product (GDP) is one of the most commonly used parameters in the presentation of regional differences in the conduct and results of the transformation process both in individual countries and across regions. Furthermore, a number of other indicators are applied that characterize changes in the economy, the so-called development of business environment, competition, foreign capital inflow, changes in social relations, etc. For a better comparison some of the indicators are calculated on a per capita basis. The study and characterization of the territorial differences by single indicators use, for comparison's sake, the mean national values of the indicators. According to Jasiulewicz (2000) these comparisons may show the "success" of changes in the territorial units.

In recent decades, alongside with the application of individual indicators the integral indicators have also been used as they turned out to be suitable for assessment and comparison of similarities and differences in the spatial differentiation of socio-economic processes and phenomena. Several researchers have examined regional transformation by integral indicators - Czyż (1998), Parysek (1998b), Ciok (2001), Nagy (2005), Tarkowski (2008) and others. The analysis shows that regardless of the number and use of various indicators, most research on territorial differences in the transformation changes is comparative in nature. Similar approach to the study of regional differences in socio-economic development of Bulgaria is applied by Yankova, Shopov, Chkorev, Ivanov, Kirilova (2003), Totev (2003), Rousev (2005), Yankova (2008) and others.

The assessment of the achieved degree of transformation in the 28 districts is done through the use of a large number of indicators selected by the author of this study to describe the essential 
features of the processes of systematic and structural transformation. Based on theoretical and methodological formulations for the study of transformation and on the availability of necessary information, it attempted to measure the achieved degree of transformation in the different districts by applying the integral (synthetic) indicator as well. The integral indicator is defined as the sum of the standardized (normalized) values of our chosen indicators characterizing economic and social aspects of transformation. The assessments of the integral indicator are based on the current statistical figures for the period 1996-2007. Some of the information is obtained from the National Statistical Institute and another part of it - from the author's publications. For most of the indicators 2007 is used as the last year; only for GDP this year is 2006. The value of the integral indicator for each district is obtained as a result of summing up the standardized (normalized) values of the chosen indicators on the basis of the formula below:

where:

$$
Z_{i}=y i_{1}+y i_{2}++y i_{3}+y i_{4}+\ldots . .+y i_{n}
$$

$Z_{i}$ is the integral indicator for the i-s territorial unit;

$\mathrm{yi}_{1, \ldots . .,} \mathrm{yi}_{\mathrm{n}}$ - the standardized (normalized) values of the chosen indicators from 1 to $\mathrm{n}$ in the i-s territorial unit.

On the basis of the categorization of the indicators, used in this research, and of the applied formula, pointed above, four synthetic intermediate indicators are calculated, which are component parts of the synthetic indicator. Depending on the nature of the processes, three of them feature various economics aspects of transformation and one - its social aspects.

It is very difficult to determine the threshold value of the integral indicator and to say with certainty that the territorial units, having values above it, are winners from the transformation process, and those with values below it, are losers. Therefore further research and concrete bases for comparisons are necessary. So at this stage we restrain from establishing such limits.

\section{Results and Discussion}

The analysis of data on gross domestic product (GDP) shows a significant territorial differentiation in areas owing to which considerable intraregional differences appear. The share of GDP produced in the economically most developed areas is growing. The analysis of the areas, holding the first and the last three positions ${ }^{1)}$ on the ranking list over the period 19992006 , indicates an increase in the share of the first three areas by 8.7 points, and a decrease in the share of the least developed areas by 0.83 points (Table 1 ).

Share from Bulgaria's Gross Domestic product

Table 1

\begin{tabular}{c|cccc}
\hline \multirow{2}{*}{ Year } & \multicolumn{2}{|c}{ First three ranking in the districts } & \multicolumn{2}{c}{ Last three ranking in the districts } \\
\cline { 2 - 5 } & Districts: & $\%$ & Districts: & $\%$ \\
1999 & Sofia-capital, Plovdiv, Burgas & 38.70 & Vidin, Smolyan, Silistra & 3.88 \\
2006 & Sofia-capital, Plovdiv, Varna & 47.40 & Vidin, Silistra, Yambol & 3.05 \\
\hline
\end{tabular}

Source: Author's calculations on the basis of the National Statistical Institute data.

1)The table uses as criteria $10 \%$ of the number of analysed territorial units. The first and the last ten districts cannot be taken into account because of the small total number of the districts in Bulgaria (28). 
Differences in GDP per capita by administrative districts point to the existing intraregional differences (Fig. 1). With values higher than the national average (6411 leva per capita) in 2006 are only 3 territorial units - the capital of Sofia, Sofia district and Varna district. A comparison with 1999 shows a decrease in the number (from 4 to 3) and a change in the "composition" of this group. In 1999 in Sofia city, and in the districts of Stara Zagora, Burgas and Vratsa the value of the discussed indicator is higher than the average for the country. The number of areas, characterized by an indicator almost equal to the national average, is reduced from 4 in 1999 (Dobrich, Varna, Kyustendil, Gabrovo) to two in 2006 (Stara Zagora, Burgas). Thus the number of districts with an indicator below the national average has grown up during the investigated period from 20 (1999) to 23 (2006). This group includes districts with better developed industries and services (Ruse, Gabrovo, Vratsa, etc.) as well districts, facing significant economic problems in recent years (Razgrad, Kyustendil, Yambol, etc.). The group of districts with the lowest index is also changing, only Montana keeps its place in it. If we "transfer" at national level the European criterion, which considers as underdeveloped (problematic, backward) territorial units with less than $75 \%$ of GDP per capita (in our case in the country), then in 2006 the number of districts, that are below that level, grew almost twice as compared to 1999 - from 9 to 17 . This comes to prove that some of the districts are lagging behind and as a result, the territorial differences between them are increasing.

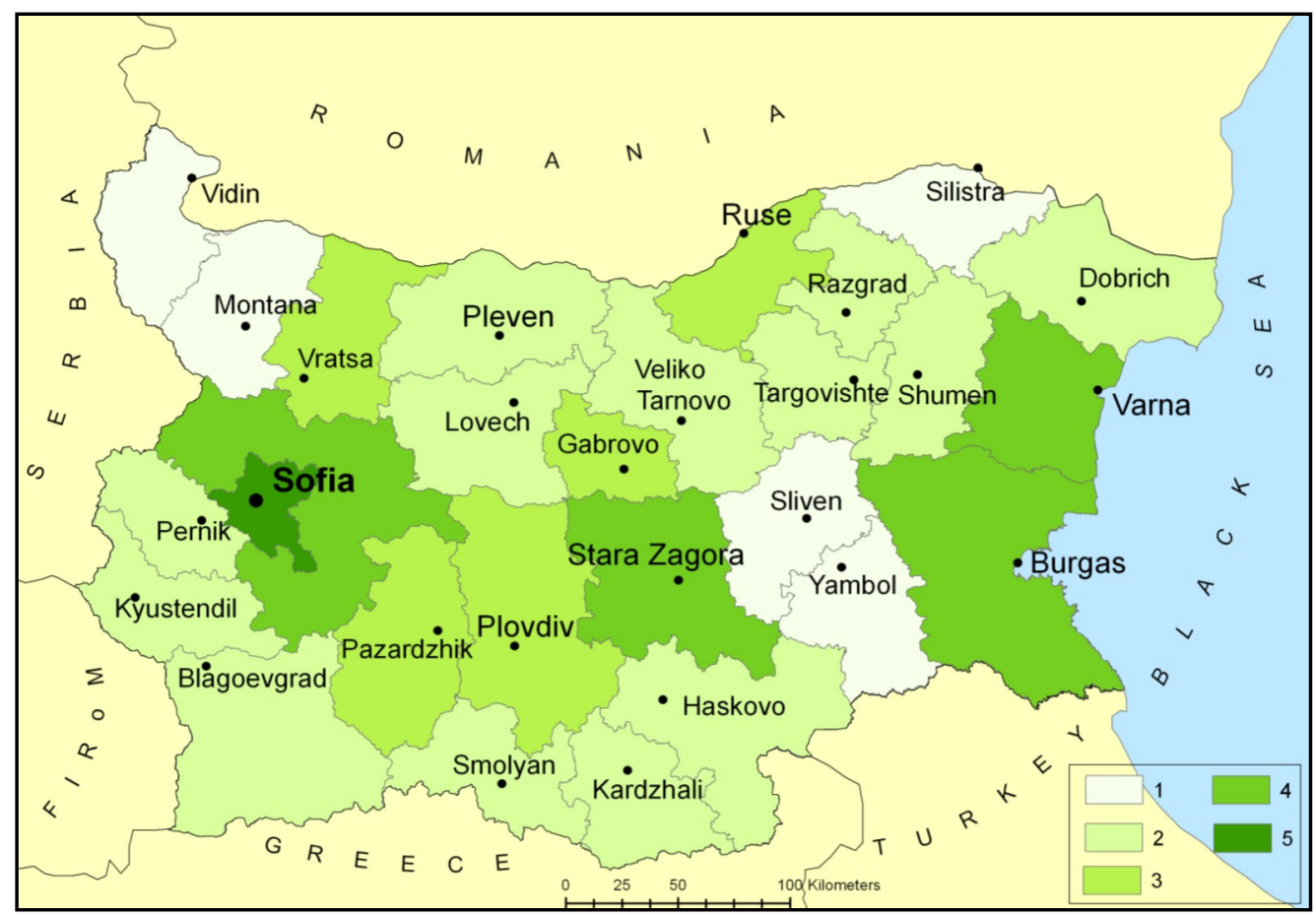

Fig. 1 - Gross Domestic Product per capita by districts (2006, leva):

1 - 3000-3999; 2 - 4000-4999; 3 - 5000-5999; 4-6000-8000; 5 - over 13000

Source of data: National Statistical Institute 
Another indicator, revealing how successful the transformation processes are in different districts, is the dynamics of changes of gross domestic product per capita in them $(1999=100)$ (Fig. 2). Gross domestic product increased in all districts but the pace of this growth is different. The comparison shows that only in 6 of the districts (the capital city of Sofia, Sofia, Pernik, Pazardzhik, Kardzhali, Varna) it is higher than the average for the country (225.7). Among them can be distinguished economically better developed districts (the capital city of Sofia, Sofia, Varna) and less developed ones (Pazardzhik, Kardzhali). What is striking is that only one of those areas is situated in northern Bulgaria (Varna) and the rest are in the south of the country. Only in two areas (Plovdiv, Smolyan) this increase is identical to the national average. In over two thirds of the districts (20) it is less than the national average. These processes indicate that most of Bulgaria's territory has slowed down the rate of its economic development.

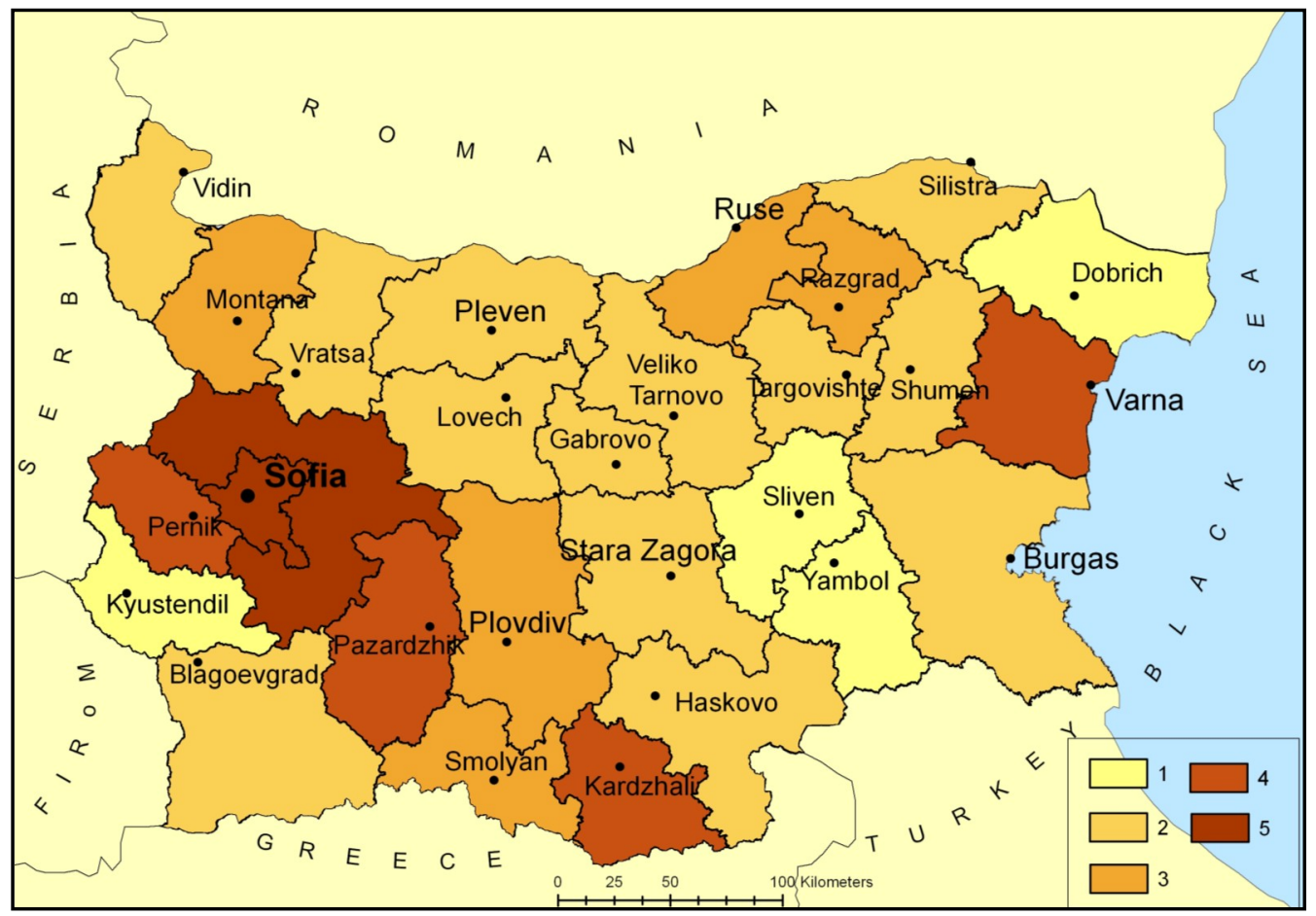

Fig. 2 - Dynamics of Gross Domestic Product per capita by Districts (1999-2006): $1999=100 ; 1$ - 140-170; 2 - 170.1-200; 3 - 200.1-230; 4 - 230.1-260; 5 - over 260.1. Source of data: National Statistical Institute

By comparing the positions of individual areas, significant differences can be noticed between the most and the least developed districts. The dispersion of areas has increased depending on their performance - from 60.4 (Kardzhali) to 173.1 (the capital city of Sofia, 1999), to 58.5 (Yambol) and to 207.7 (the capital city of Sofia, 2006). Besides, the scale of dispersion increases, too - up to 3.55 in 2006 (Table 2). A similar scale of dispersion between the least and most developed voivodships in Poland (1:3.4) is established by Czyz (1998). The annual differences between districts in Bulgaria are up to twice as great as those in the planning regions. Similar ratios and changes are found by Hungarian research scientists between 
NUTS2 and NUTS3, ranked in the best and the worst position in Hungary in 1994-2000 (Hrubi 2002).

Table 2

Differences between districts by Gross Domestic Product per capita

\begin{tabular}{|c|c|c|c|c|c|c|c|c|c|c|c|}
\hline & 1996 & 1997 & 1998 & 1999 & 2000 & 2001 & 2002 & 2003 & 2004 & 2005 & 2006 \\
\hline $\begin{array}{l}\text { The best position to the } \\
\text { worst position }\end{array}$ & 2.87 & 2.21 & 2.51 & 3.02 & 2.63 & 3 & * & * & * & * & 3.55 \\
\hline $\begin{array}{l}\text { The best position to the } \\
\text { worst position without } \\
\text { Sofia- capital }\end{array}$ & 1.92 & 1.02 & 1.98 & 2 & 2.05 & 1.88 & * & * & * & * & 1.97 \\
\hline $\begin{array}{l}\text { The best position to the } \\
\text { second (best) position }\end{array}$ & 1.4 & 1.02 & 1.27 & 1.51 & 1.28 & 1.6 & * & * & * & * & 1.80 \\
\hline
\end{tabular}

*- not calculated due to lack of data

Source: Author's calculations on the basis of the National Statistical Institute data

If the capital of Sofia is not taken into account, then the differences between the districts will decrease significantly, and the changes in the ratios between the districts in best and worst position will be negligible. The analysis shows that by 2000 the changes in the districts, ranked second, are more frequent than those concerning the areas in the worst position. Recently the gap between the poorest districts is relatively small and therefore different areas take turns, occupying the worst position.

For calculation of integral indicators for the different districts are selected 25 single indicators. Among the indicators such ones are selected that would enable not only to assess the results of the socio-economic transformation, but also the overall changes in these processes through the dynamics of changes in some indicators for which comparable information for the surveyed period (1999-2006 d .) is available. An analysis of the relationship between standardized values of GDP per capita, determined by many authors as the most important indicator for measuring the socio-economic transformation, and the other 24 selected indicators, shows different interactions between them. The indicators characterizing the dynamics of the GDP per capita, GVA structure, FDI per capita, fixed assets per capita, density of population and employment by areas, etc. (10 in number) have the lowest correlation coefficients - of $-0,01$ (dynamics of the unemployment rate) to 0.58 (dynamics of the share of services in GVA). The only exception is the dynamics of population density (0.65). Therefore, the indicators characterizing the dynamics of change are not included in the calculation of the integral indicator. The cluster analysis, using the method of nearest neighbour, characterizes the relationship between standardized values of these parameters (Fig. 3). The highest is the interdependence between GDP per capita, FDI per capita, the existing fixed assets and the expenditure on acquisition of tangible fixed assets per capita which form a cluster. The lowest is the interdependence between some indicators, characterizing the economic restructuring (e.g. the share of agriculture in GVA, GVA in the private sector) and the social impact of socioeconomic transformation (e.g. the unemployment rate, the income per capita). Since these indicators are important for characterizing certain aspects of the transformation process, all 15 indicators are used to determine the integral index. 


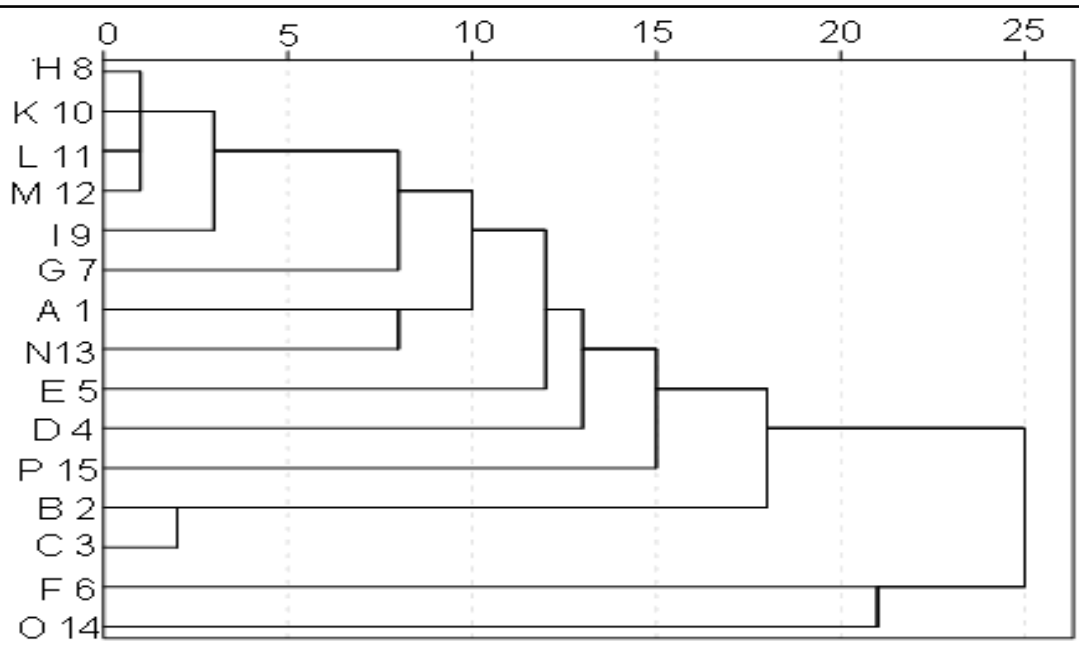

Fig. 3 - Dendogram using the method of nearest neighbor

Indicators: A1 - share of employees in the private sector of the total number of employees; B2 share of production of GVA in private sector; C3 - share of fixed assets in the private sector; D4 - share of the services in GVA; E5- share of the industry in GVA; F6 - share of the agriculture in GVA; G7 - number of enterprises, excl. financial, in 1000 persons of the population; H8 GDP per capita; 19 - population density, K10 - FDI in the non-financial enterprises per capita; L11 - fixed assets in the non-financial enterprises per capita; M12 - expenditure on acquisition of tangible fixed assets in the non-financial enterprises sector per capita; N13 - employment rate; 014 - unemployment rate; P15 - income per capita.

\section{Source: author's calculations based on National Statistical Institute data}

The selected and applied 15 indicators can be conditionally divided into several groups. Taking into consideration the theoretical and methodological formulations for the study of transformation, the specific features of the ongoing processes and the availability of necessary information for their characterization, the calculated integral (synthetic) indicator for measuring the achieved degree of transformation in the different districts is sub-divided into four main components (integral intermediate indicators). Three of them, conventionally called "change of ownership" (I), "restructuring" (II), "obtained level of development and influencing factors" (III) feature various aspects of economic transformation and one, conventionally called "social consequences" (IV), refers to the social aspects of transformation (Table 3). The analysis of these four integral intermediate indicators makes it possible to assess them according to the territorial differences between the areas.

The first integral intermediate indicator $\left(\mathrm{Zl}_{\mathrm{i}}\right)$ characterizes the changes in ownership in each territorial unit as one of the major changes in the process of transformation. It is calculated on the basis of three indicators by using the following formula:

$\mathrm{Zl}_{\mathrm{i}}=\mathrm{yi} \mathrm{i}_{1}+\mathrm{yi}_{2}+\mathrm{yi}_{3}$

where:

$\mathrm{yi}_{1}$ - the standardized value of the share of employees in the private sector of the total number of employees in the i-s territorial unit;

$\mathrm{yi}_{2}$ - the standardized value of the share of production in private sector gross value added 
(GVA) in the i-s territorial unit;

$\mathrm{yi}_{3}$ - the standardized value of the share of fixed assets in the private sector in the i-s territorial unit;

In order to determine the second integral intermediate indicator for the i-s territorial unit $\left(\mathrm{ZII}_{\mathrm{i}}\right)$, characterizing the process of economic restructuring, 4 indicators have been used:

$\mathrm{ZII}_{\mathrm{i}}=\mathrm{yi}_{4}+\mathrm{yi}_{5}+\mathrm{yi}_{6}+\mathrm{yi}_{7}$

where:

$\mathrm{yi}_{4}$ - the standardized value of the share of the services in GVA in the i-s territorial unit;

$\mathrm{yi}_{5}$ - the standardized value of the share of the industry in GVA in the i-s territorial unit;

$\mathrm{yi}_{6}$ - the standardized value of the share of the agriculture in GVA in the i-s territorial unit;

$\mathrm{yi}_{7}$ - the standardized value of the coefficient of entrepreneurship (number of enterprises, excl. financial, in 1000 persons of the population) in the i-s territorial unit;

The available information favors the application of 5 indicators for calculating the third integral intermediate indicator $\left(\mathrm{ZIII}_{\mathrm{i}}\right)$, characterizing the achieved level of development of the territorial units and some more important factors which speed up / slow down the transformation processes in each territorial unit:

$\mathrm{ZIII}_{\mathrm{i}}=\mathrm{yi}_{8}+\mathrm{yi}_{9}+\mathrm{yi}_{10}+\mathrm{yi}_{11}+\mathrm{yi}_{12}$

where:

$\mathrm{Yi}_{8}$ - the standardized value of the GDP per capita in the i-s territorial unit;

$\mathrm{yi}_{9}$ - the standardized value of the population density in the i-s territorial unit;

$\mathrm{yi}_{10}$ - the standardized value of the FDI in the non-financial enterprises per capita in the i-s territorial unit;

$\mathrm{yi}_{11}$ - the standardized value of the fixed assets in the non-financial enterprises per capita in the i-s territorial unit;

$\mathrm{yi}_{12}$ - the standardized value of the expenditure on acquisition of tangible fixed assets in the non-financial enterprises sector per capita in the i-s territorial unit;

The fourth integral intermediate indicator for each territorial unit $\left(Z_{\mathrm{IV}}\right)$ characterizes the social consequences of transformation. The unemployment rate is in inverse proportion to the progress of transformation processes, so it has a minus sign in the formula used.

$\mathrm{ZIV}_{\mathrm{i}}=\mathrm{yi}_{13}-\mathrm{yi}_{14}+\mathrm{yi}_{15}$

where:

$\mathrm{yi}_{13}$ - the standardized value of the employment rate in the i-s territorial unit;

$\mathrm{yi}_{14}$ - the standardized value of the unemployment rate in the i-s territorial unit;

$\mathrm{yi}_{15}$ - the standardized value of the income per capita in the i-s territorial unit;

The analysis of these four synthetic intermediate indicators, conventionally called "change of ownership" (I), "restructuring" (II), "obtained level of development and influencing factors" (III) and "social consequences" (IV), makes it possible to assess them according to the territorial differences between the areas. As to the change in ownership, the differences between them are relatively small. The only exception is Vratsa district in which the state-owned manufacturing firms play an important role (NPP Kozlodui, etc.). According to the values of the second intermediate indicator, the best results in the economic restructuring have been achieved in the capital city of Sofia, and in the districts of Varna and Burgas. The most significant differences in the values of the intermediate indicator "obtained level of development and influencing factors", where the district of Sofia-city is remarkable for a very high positive value and 21 of the areas have negative ones - from -0,01 (Pernik) to -3.02 (Montana). There are essential differences in the values of the intermediate indicator characterizing the social consequences (Table 3). 
Integral indicator of the achieved degree of socio-economic transformation by districts

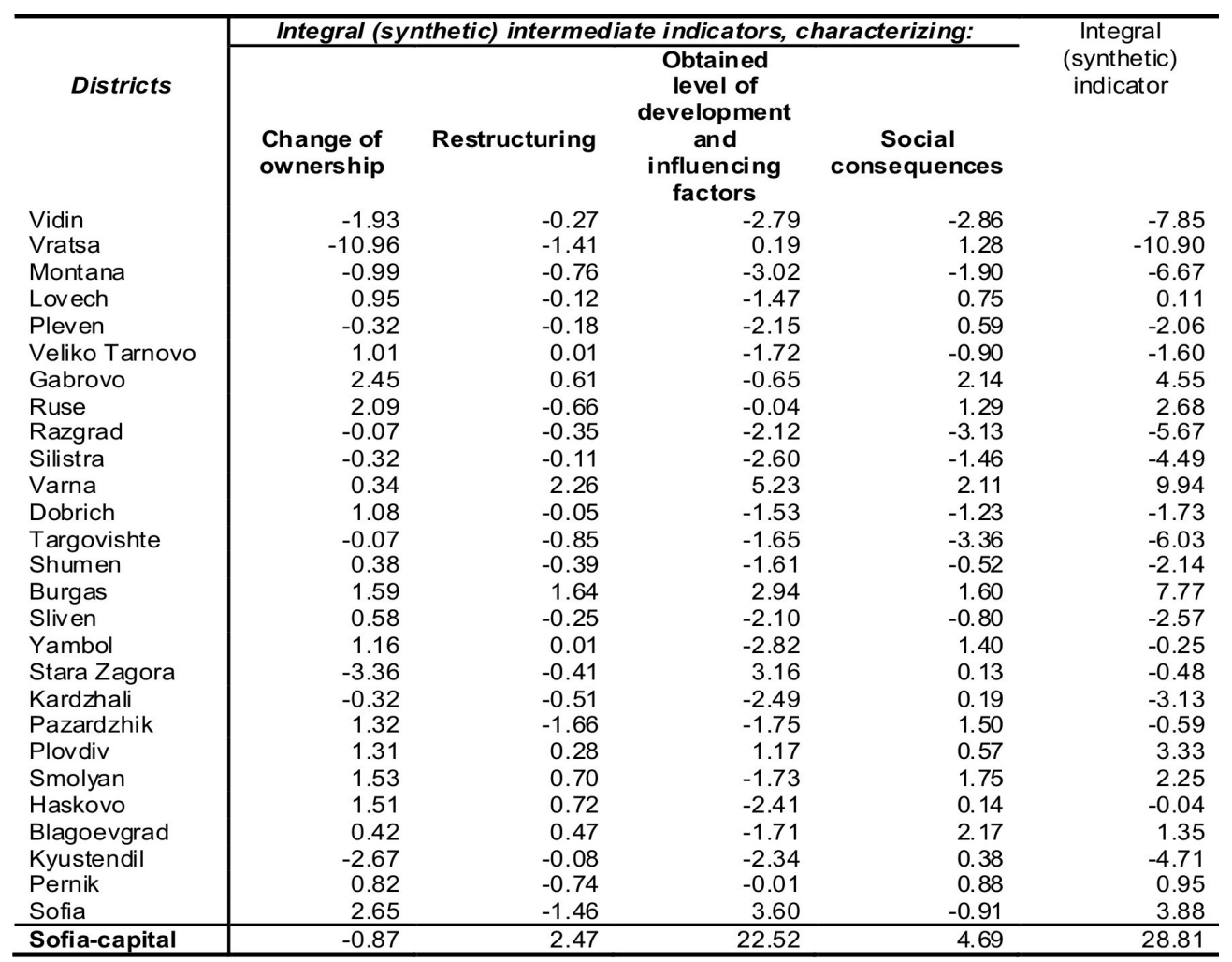

Source: Author's calculations on the basis of the National Statistical Institute data

The integral indicator allows to assess the regional differences depending on the aggregate effect of all indicators. An analysis of the calculated values by districts shows that they widely vary - from -10.90 (Vratsa) to 28.81 (Sofia-city). Only 11 of the areas have a positive value of the integral indicator, while the remaining 17 have a negative one (Table 3 ). These differences are a quite natural, resulting from the utilization of the existing socio-economic potential, from the transformation crisis in the early 1990s, from the disparities in the course of transformation processes, etc. The analysis shows that the majority of territorial units in North Bulgaria have negative (10 from 14 areas) or low values of the integral indicator (Lovech). The districts of Varna, Gabrovo and Ruse make an exception (Table 3). Most of the areas with positive values are located in South Bulgaria. This once again confirms the major territorial disparities between North and South Bulgaria. The differences between North and South Bulgaria are outlined by Stoyanov, Dimov (2006), who claim that "a stable south-to-north dichotomy in GDP is arising. The trend towards the increasing weight of the South is persistent, which demonstrates the growing imbalances" (after Stoyanov 2008, p. 367).

The highest value of the integral indicator is recorded in the capital city of Sofia. Similar is the place of Budapest as compared to the other territorial units in Hungary, where according to Enyedi (2005) "in economic performance, the most significant regional change has been the 
outstanding success of the Budapest Metropolitan Region, producing a growing gap between the capital city and the rest of the country" (p. 19). The current situation, conditions and prospects for future developments give grounds to assume that the differences between the capital city of Sofia and other districts will grow in the coming years. The role of the capital cities in regional development, where are concentrated the most important elements of market economy, is observed by Horvath (2009) in almost all countries of Central and Eastern Europe. According this author this adverse and long territorial concentration must be changed. Fassmann (2000), Enyedi (2005), Tarkowski (2008), Stoyanov, Dimov (2006), Horvath (2009) and other authors emphasize in their own research the growing role of the capital, metropolitan and big cities in different countries.

Bulgaria's districts Varna and Bourgas come second after Sofia with significantly lower integral indicators. The value of their integral indicators differ considerably from calculated values of other areas. Against the background of the other areas in Bulgaria, Sofia-capital, Varna and Burgas districts can be conditionally defined as winners from transformation. Of course, it goes without saying that in comparison with NUTS3 in the EU configuration, even the capital city of Sofia is among the EU underdeveloped territorial units of that type. With the lowest integral indicator are the districts of Vratsa, Vidin, Montana, Targovishte and Razgrad (Fig. 3). They can certainly be treated as the greatest losers from transformation.

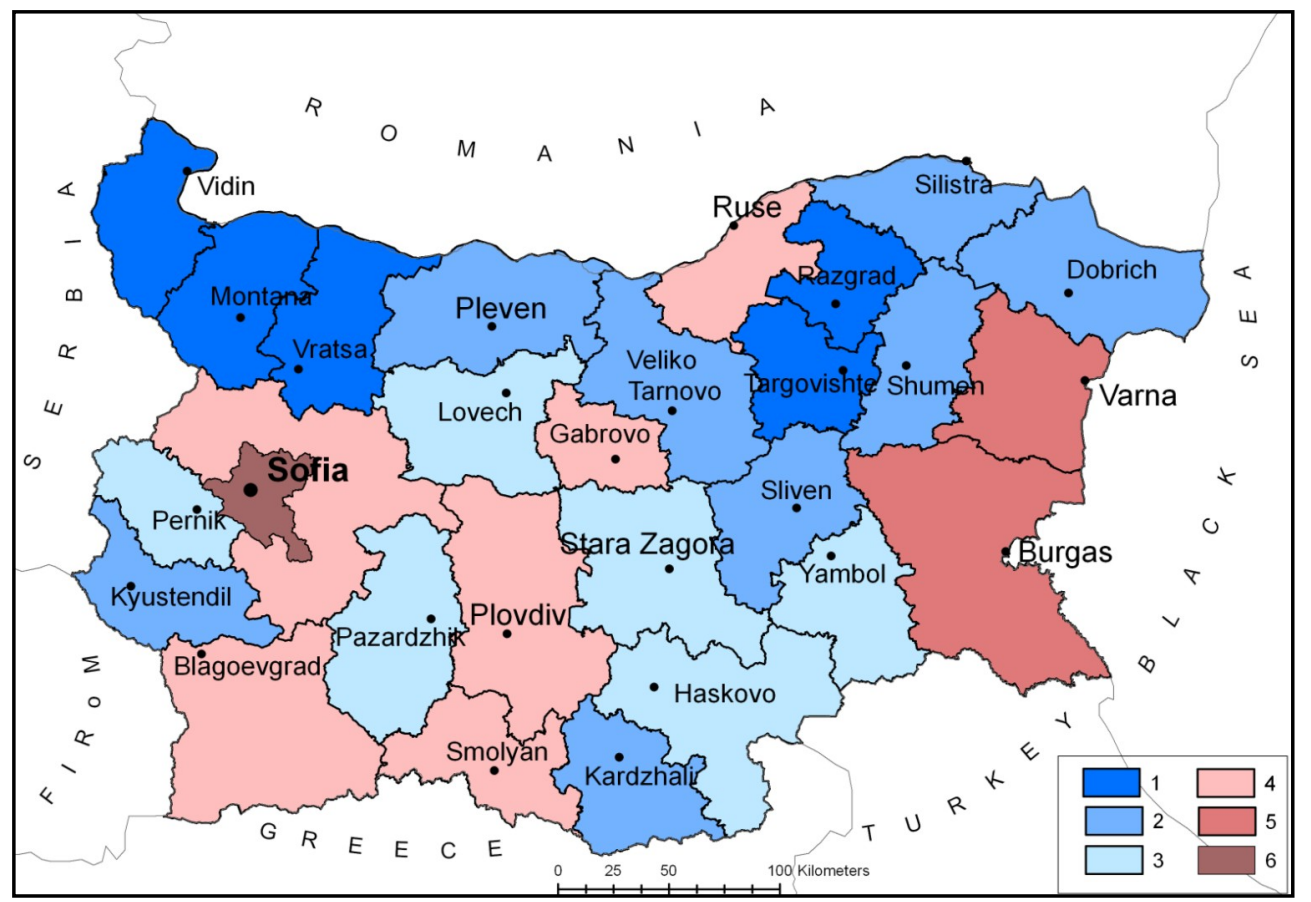

Fig. 4 - Achieved degree of the socio-economic transformation.

Value of integral indicator: 1 - from -10.9 to $-5.1 ; 2-$ from -5 to $-1.1 ; 3-$ from -1 to $1 ; 4-1.1-5$; 5 - 5.1-10; 6 - over 28.

Source: Author's calculations on the basis of the National Statistical Institute data

An impact on the existing and growing regional disparities has the greater spatial differentiation 
that existed earlier, in the period of planned economy. In Bulgaria as well as in other Central and East European countries during the period of territorial restructuring "the leading and backward areas have been developing at quite different paces, which indicates that the special structuring forces are now more differentiated than they were in the planned economy period. Back then, planned industrialization was to shape the economic potentials of the various regions; today, their economic development is influenced by the competitive sectors of industry and by adjoining services" (Horvath, 2009, c. 11). "In many respects regional disparities are exacerbated or significantly modified due to uneven crisis processes in different sectors and branches of national economy" (Roussev, 2005, p. 152).

The development of the transformation process has a definite influence on the polarization of development in different parts of the territorial units and thus on the formation of regional differences at a lower level. According to Horvath (2009) significant intra-regional disparities between districts and municipalities in Bulgaria indicate that „the regional development policy has so far failed to adequately address" (c. 12).

Szlachta (1993), Fassmann (2000), Enyedi (2005), Horvath (2009) and other authors identify as winners from the processes of transformation the metropolitan, capital and big cities, and as losers - the industrial cities or areas in which heavy and mining industries are dominant. To the "winners" Fassmann (2000) adds border and rural areas defined as islands of stability. Perhaps the latter is valid for some countries with smaller or more successful reforms in agriculture, but for Bulgaria this finding is not definitely confirmed. Enyedi (2005) and Horvath (2009) include the rural areas in the group of losers, too. Horvath (2009) regards as losers from this transformation the regions with extensive agriculture and suggests that this is a special EastEuropean characteristic feature. This study shows that the districts, which embrace vast rural areas, have low values of the integral indicator, e. g. most of the districts in North Bulgaria (Fig. 3).

According to Fassmann (1997) one of the regional consequences of the transformation measures is the increased importance of urban centers as growth poles of the national economy. The largest agglomerations in Bulgaria - Sofia, Plovdiv, Varna-Devnya, BurgasKameno, are formed in area, characterized in this study by a high degree of socio-economic transformation (Fig. 3). As economically better developed, they are in a favorable situation, "have experienced more easily the difficulties of restructuring and have been given better chances to attract investors, including foreign ones " (Parysek 1998a, p.40).

Of the other big cities in Bulgaria (Ruse, Stara Zagora, Pleven) only Pleven is a core of an urban agglomeration (lliev, 1995). The calculated integral indicator for the district of Pleven is negative (Table 3). Further details of studies on the role of urban agglomerations and cities in Bulgaria in the process of transformation will allow to determine the effectiveness of the socioeconomic transformation in them and the extent of their impact over the respective areas.

According to Tarkowski (2008) the regional differences according to the theory of polarization, must grow in the conditions of functioning market economy. As Czyz (1998) points out that during the transformation regional polarization of socio-economic development takes place, which is a challenge for an active regional policy. It will contribute a lot to the sustainable and balanced development of different territorial units in the country. 


\section{Conclusions}

This investigation presents the territorial differences of transformation process in Bulgaria by 28 districts (NUTS3) on the basis of analysis of a single indicator (GDP per capita) and the calculated values of integral indicator. Significant differences in the transformation process in the country are observed in its course in the individual units. They are more or less apparent depending on the available economic potential in them and its current state, on the degree of influence of factors at national and local level (geographical location, economic structure, attractiveness to foreign investment, demographic factors, created jobs, differences in income, infrastructure and communications, etc.), on differences in the rate of reforms, etc.

The study shows that the majority of territorial units in North Bulgaria have negative or low values of the integral indicator in contrast to the areas with positive values in South Bulgaria. This once again confirms the major territorial disparities between North and South Bulgaria. The best results in transformation are achieved in Sofia-capital, in Varna and Burgas districts. Against the background of the other areas in Bulgaria, Sofia-capital, Varna and Burgas districts can be conditionally defined as winners from transformation. But in comparison with NUTS3 in the EU configuration, even the capital city of Sofia is among the EU underdeveloped territorial units of that type. The districts with the lowest integral indicator (Vratsa, Vidin, Montana, Targovishte and Razgrad) can certainly be treated as the greatest losers from transformation.

\section{References}

CIOK, S. (2001), Processes of socio-economic transformation processes in countries of Central and Eastern Europe in light of selected indexes, in: Kitowski, J. (ed.) Spatial dimension of socio-economic transformation processes in Central and Eastern Europe on the turn of the $20^{\text {th }}$ century, vol.l, Rzeszów: 35-50.

CONFORD, J., RICHARDSON, R., SOKOL, M., MARQUES, P., GILLESPIE, A. (1996), Transformation of regional societies throught ICTs: State(s) of the Art(s), A discussion document, Final version July 2006, Sixth Framework Programme.

CZYŻ, T. (1998), Polarisation of regional development during the period of socioeconomic transformation in Poland, in: Parysek, J, H. Rogacki, Przemiany społecznogospodarcze Polski lat dziewięćdziesiątych, BWN, Suliborski Poznań (in Polish).

ENYEDI, G. (2005), Processes of regional development in Post-socialist Hungary, in: Barta, G., Fekete, E.G., Szorenyjne, I.K., Timar, J., Hungarian Spaces and places: patterns of transition, Pecs: 18-27.

FASSMANN, H. (1997), Regionale Transformationsforschung. Theoretische Begrundung und empirische Beispiele, in: Regionale Transformationsprozesse in Europa. Beiträge zur Regionalen Geographie, 44. Leipzig.

FASSMANN, H. (2000), Regions in upheaval. Conceptual framework and empirical findings of the regional transformation research, in: Horvath, G. (ed.), Regions and cities in the global world, Pecs: 126-140.

HORVATH, G. (2009), Cohesion Deficiencies in Eastern and Central Europe Inequalities of Regional Research Area, DISCUSSION PAPERS, No 72, Centre for Regional Studies of Hungarian Academy of Sciences, Pecs.

HRUBI, L. (2002), Old and new elements in the spatial structure of Hungary in the 1990s, in: Horvath, G. (Ed.), Regional Challenges of the Transition in Bulgaria and Hungary, DISCUSSION PAPERS, Special Issue, Centre for Regional Studies of Hungarian Academy of Sciences, Pecs.

ILIEV, I. (1995), Formation of Pleven agglomeration and anthropogenic transformation 
of its territory, Dissertation, Sofia, 1995 (typewritten), (in Bulgarian).

JASUILEWICZ, M. (2000), Structural and spatial transformations of Central Pomerania's rural areas in the period of system transformation, Politechnika Koszalinska, Koszalin, (in Polish).

NAGY, G. (2005), Changes in the position of Hungarian regions in the county's Economic field of gravity, in: Barta, G., Fekete, E.G., Szorenyjne, I.K., Timar, J., Hungarian Spaces and places: patterns of transition, Pecs.

PARYSEK, J. (1998a), Effects of socioeconomic transformation process in Poland. Balance of period 1989-1996, in: Parysek, J., Rogacki, H. (Eds.), Przemiany społecznogospodarcze Polski lat dziewięćdziesiątych, Bogucki Wydawnictwo Naukowe, Poznań; (in Polish)

PARYSEK, J. (1998b), The spatial dimension of the process of socio-economic transformation (in the first 6 years), in: Domański, R. (ed.), Emerging spatial and regional structures of an economy in transition, Warszawa, PWN.

ROUSEV, M. (2005), Rank and typology of districts and municipalities in Bulgaria in terms of sustainable development, Godishnik na SU, kn. 2, Geografia, t. 97: 151-159, (in Bulgarian)

RYDZ, E. (2006), Change of socio-economic structures during period of system transformation in Pomorze Środkowe, Słupsk, Wyd. Pomorskiej Akademii w Słupsku, (in Polish).

STOYANOV, P. (2008), German "organization of space", Habilitation work. Sofia (typewritten), (in Bulgarian).

SZLACHTA, J. (1993), Regional development of Poland in economic transformation conditions, Fundacja im. F. Eberta, Warszawa, (in Polish).

TARKOWSKI, M. (2008), Centres and perypheries socio-economic development in Poland under system transformation, Gdynia-Pelplin, (in Polish). Bulgarian).

TOTEV, S. (2003), Regional dimensions and overcoming differences, Ikonomika, 3, (in

YANKOVA, N. (2008), Development differences between territorial units in the country during the period 2003-2004, Economic studies, 1: 58-84, (in Bulgarian).

YANKOVA, N., SHOPOV, G., CHKOREV, N., IVANOV, S, KIRILOVA, Y. (2003), Socio-economic differences between municipalities in Bulgaria, Sofia, (in Bulgarian).

ZIOŁO, Z. (red.), (1998), Problemy transformacji struktur regionalnych $w$ procesie zmian systemu gospodarowania integracji europejskiej, Rzeszów,

Initial submission, October 2, 2010

Revised submission, January 4, 2011

Final acceptance, April 28, 2011

Correspondence: National Institute of Geophysics, Geodesy and Geography, Bulgarian Academy of Sciences, "Acad.G.Bonchev" str., bl.3, 1113 Sofia, Bulgaria; Institute of Geography, Kazimierz Wielki University, Minska 15, 84-428, Bydgoszcz, Poland.

E-mail: ilieva_mm@abv.bg 